\title{
Epicureanism and Skepticism about Practical Reason
}

\author{
Christopher Frugé (D) \\ Department of Philosophy, Rutgers University, New Brunswick, NJ, USA \\ Email: Christopher.Fruge@rutgers.edu
}

\begin{abstract}
Epicureans believe that death cannot harm the one who dies because they hold the existence condition, which states that a subject is able to be harmed only while they exist. I show that on one reading of this condition death can, in fact, make the deceased worse off because it is satisfied by the deprivation account of death's badness. I argue that the most plausible Epicurean view holds the anti-modal existence condition, according to which no merely possible state of affairs can be good or bad relative to the subject who dies. I go on to show how this condition, as well as any other condition that denies the deprivation account, results in skepticism about practical reason. Thus, the Epicurean faces a dilemma. Either our practical reasoning is hopelessly mistaken or death can make us worse off. Given that our practical reasoning seems at least mildly reliable, we should conclude that death can make us worse off.
\end{abstract}

Keywords: death; Epicureanism; deprivationism; existence condition; practical reason; modality; relativism

Epicureanism is a paragon of consolationist philosophy. Death, according to the Epicurean, cannot be good or bad for the one who dies. We should therefore neither regret a death that prevents us from continuing to live a flourishing life, nor should we welcome a death that prevents us from suffering. The Epicurean believes this because they are committed to the existence condition, according to which anything that is good or bad for a subject must occur while that subject exists. Epicurus tells us that "death, therefore, the most awful of evils, is nothing to us, seeing that, when we are, death is not come, and, when death is come, we are not" (Epicurus 1997). There are two arguments that we can extract from this passage, and each involves commitment to the existence condition as a thesis about value. The first argument is the no subject problem. If death were to be good or bad for us, then it would do so while we are dead. But when we are dead we do not exist, and so we are unable to be harmed or benefited at all. This argument assumes the existence condition as a premise. The second argument is the timing problem. Anything that is bad or good for a subject must be good or bad for them at some time. Death cannot be good or bad for the subject at any time, and so death cannot be good or bad for the one who dies. The timing problem does not assume the existence condition but instead leads to it as long as we can run a timing problem argument against any posthumous state of affairs. But regardless of the Epicurean's preferred argument, they must hold the existence condition as a thesis about value if they want to maintain that death can never make the one who dies worse or better off. According to deprivationism, death can make the one who dies worse off if they would have had a better life were they to have gone on living, and death can make the one who dies better off if they would have had a worse life were they to have gone on living. In order to block deprivationism, the Epicurean needs to hold the existence condition, but, as I argue in this paper, the existence condition leads to a skepticism about practical reason.

In the first section of this paper, I discuss the no subject and timing problems and show how each requires that the Epicurean be committed to the existence condition. I then show that the existence condition as normally understood actually fails to entail that death cannot make the one who dies 
worse off and is in fact satisfied by the deprivation account of death's badness. In the second section, I argue that the most plausible version of Epicureanism that denies deprivationism must hold the anti-modal existence condition, which precludes any merely possible but nonactual state of affairs from being possible goods or bads at all. In the third section, I show that this condition results in our practical reasoning about our own wellbeing being radically mistaken, and in the fourth section I show that the same is true for any view that denies the deprivation account. Indeed, by the Epicurean's own lights, even nearly ideal agents are almost always guaranteed to be radically mistaken in their value judgments. Hence, Epicureanism should be rejected if practical reason is even a remotely reliable guide to value.

\section{The existence condition}

The Epicurean holds that death cannot harm the deceased. As I understand the view, the Epicurean is making a claim about the state of being dead, and they are not making any claims about the event of death or the process of dying. So, while I often use the word "death" instead of the more laborious "state of being dead," throughout I mean to be speaking of the state of being dead.

Traditionally, the Epicurean position has been characterized by commitment to the following condition on harm:

Existence Condition: A state of affairs harms a subject only if the subject exists at the time the state of affairs obtains (cf. McMahan 1988, 33; Feldman 1991, 205; Kagan 2012, chaps. 9-10; Silverstein 1980, 402).

Some Epicureans hold a stronger experience condition. One extreme version comes in the form of a strong hedonism, according to which one must actually have a conscious experience of something in order to be harmed by it (Green, O. H. 1982, 100). A more moderate version is that one must be able to be causally affected by something in order to be harmed by it (Rosenbaum 1986). However, in this paper, I focus on variants of the existence condition. Any experience condition would entail some sort of existence condition given that one must exist in order to experience something or to be able to be causally affected by it. The problems that arise for the existence condition and its variants infect these stronger views and their variants.

The existence condition, as stated above, is ambiguous between a weak and a strong reading:

Weak Existence Condition: A state of affairs is finally good or bad for a subject only if the subject exists at the time the state of affairs obtains.

Strong Existence Condition: A state of affairs is finally or instrumentally good or bad for a subject only if the subject exists at the time the state of affairs obtains.

Here and throughout, I assume that states of affairs can't obtain at fusions of times, so a state of affairs can obtain at a time $t$ but not at the fusion of $t$ and some other time $t^{\star}$ even if that fusion contains $t$. If one doesn't like this assumption, one can reformulate the conditions so they hold that a state of affairs can be good or bad for a subject only if there is some fusion of times at which it obtains such that the subject is alive at all times in that fusion. This makes it so that states of affairs that obtain atomically at a time $t^{\prime}$ after the time of the subject's death cannot be good or bad for them because any fusion at which that state of affairs obtains must contain at least $t^{\prime}{ }^{1}$.

As another point of clarification, a final good raises well-being by itself, and a final bad lowers well-being by itself. An instrumental good either leads to something else that raises well-being or it prevents something from coming about that would lower well-being. An instrumental bad either

${ }^{1}$ For a fusionist approach to the time of death's harm, see Duncan Purves (2017). 
leads to something else that lowers well-being or it prevents something from coming about that would raise well-being. Some philosophers use "intrinsic" to mean what I mean by "final," and some philosophers use "extrinsic" to mean what I mean by "instrumental." The weak existence condition amounts to the claim that a subject's well-being can only be raised or lowered at times that they exist, because any such raising and lowering must be in virtue of the subject accruing some final good or bad. This is an unimpeachable condition, but, as I will show, the deprivation account of death's harm satisfies it. The strong existence condition goes further in holding that something cannot be instrumentally good or bad for a subject if it obtains while they do not exist. ${ }^{2}$

There are a variety of ways we can understand the strong existence condition, and I discuss them in the next section, but before getting to that it will be useful to first see why Epicureanism must be committed to something like it in the first place. The plan is as follows. I first discuss the two most prominent arguments for Epicureanism and argue that each involves some sort of existence condition. I then discuss the deprivationist view of how death can make our life go better or worse and show how, in order to deny this, the Epicurean needs to uphold something like the strong existence condition. Hence, regardless of how the Epicurean might argue for their position, they must at least commit themselves to something along the lines of the strong existence condition on pain of allowing a deprivationist account of death's harm or benefit.

Let's start by taking a look at the arguments. The no subject problem argument goes as follows:

1. States of affairs can only be good or bad for us if they obtain at times we exist.

2. When we're dead, we do not exist.

3. Hence, the state of being dead cannot be good or bad for the one who dies.

This argument assumes the existence condition as the first premise, and so any Epicurean that invokes it must be committed to the truth of the existence condition.

The timing problem argument goes as follows (cf. Bradley 2009, chap. 3; Johansson 2012):

1. Anything that is good or bad for a subject can only be good or bad for them at some time.

2. There is no time at which death is good or bad for the one who dies.

3. Hence, death cannot be good or bad for the one who dies.

Following Ben Bradley (2009, chap. 3.3), we can understand this argument as working by elimination. Given the first premise, the Epicurean looks at each answer as to the time death is purportedly good or bad for us and argues that it is a bad answer. Understood in terms of the state of being dead as opposed to the event of death, some candidate answers as to when death is good or bad are:

Priorism: The state of being dead is good or bad for the subject prior to the time of the event of their death (Pitcher 1984; Luper 2007).

Concurrentism: The state of being dead is good or bad for the subject at the time of the event of their death.

Subsequentism: The state of being dead is good or bad for the subject after the event of their death (Bradley 2009, 88-92).

Eternalism: The state of being dead is eternally good or bad for the subject who dies (Feldman 1991).

Fusionism: The state of being dead is good or bad for the subject at some fusions of times $t$ and $t^{\star}$, where $t$ is during the life of the subject and $t^{*}$ is after the event of their death (Purves 2017).

${ }^{2}$ I thank an anonymous reviewer for suggesting some better terminology than I had used originally. 
Each of these answers serves as a denial of the second premise. Additionally, there is the view that denies the first premise by denying that death is good or bad for the subject at any time:

Atemporalism: The state of being dead is good or bad for the subject, but not at any time ${ }^{3}$ (cf. Johansson 2012, sec. 7).

This paper is not the place to assess these various answers to the timing problem, but it is clear that for the timing problem argument to be successful, the Epicurean needs to reject each one. This means they are committed to the claims that any good or bad must be good or bad for the subject at some time and that there is no time at which death is bad. However, the state of being dead is not a unique posthumous state of affairs with respect to the time it occurs. ${ }^{4}$ Indeed, any posthumous state of affairs occurs, like the state of being dead, after the subject has died. It seems, then, that if the timing problem is successful against death being a good or bad, then it would be successful against any other posthumous state of affairs being good or bad. But to deny that any posthumous state of affairs can be good or bad for us entails the existence condition-setting aside states of affairs that obtain before our birth, which aren't at issue in this paper. This is because if no posthumous states of affairs can be good or bad for us, then the only states of affairs that can be good or bad for us are ones that obtain while we're alive. Therefore, the timing problem-so long as it is treated as a problem for any posthumous state of affairs and not just death-leads to the existence condition.

However, I won't discuss either the no subject problem or the timing problem because regardless of how the Epicurean argues for their view, they must be committed to the existence condition-in particular, something like the strong existence condition-if they are to ensure that death can never make the one who dies worse or better off. To see this, it helps to think about the following sense of harm. Call this sense $\operatorname{harm}_{D}-D$ for deprivation:

state of affairs $X$ that obtains at $t$ in world $w$ harms ${ }_{D}$ subject $s$ in $w={ }_{d f} X$ obtains at $t$ in world $w$ and the lifetime well-being of $s$ in $w$ is lower than the lifetime well-being of $s$ in a relevant world $v$ where $X$ does not obtain ${ }^{5}$ (cf. Timmerman 2019, sec. 3.1).

If something harms ${ }_{D}$ a subject, it does so because in a relevant possible world where that thing didn't obtain, the subject does better overall. Having one's arm chopped off is harmful $\mathrm{D}_{\mathrm{D}}$ because one would have done better with one's arm. Crucially, the possible world of comparison must be relevant. Otherwise for any state of affairs we can find some possible world such that the state of affairs doesn't occur and the overall lifetime well-being of the subject is higher-just make the world of comparison a world of eternal bliss. Therefore, we need to appeal to worlds that are similar to the one in which the state of affairs obtains. What counts as similarity and relevance is a tricky issue about which I have nothing informative to say, so I'll have to appeal to an intuitive grasp of the conditions on relevance. Yet, it is clear that one constraint is that the subject has the same level of lifetime well-being in $w$ and $v$ up until the time the state of affairs that harms $s_{\mathrm{D}}$ them obtains.

Death can harm ${ }_{D}$ by depriving a subject of goods that they would have obtained had they gone on living (Nagel 1994). The best form of this deprivation theory is formulated in terms of possible worlds:

\footnotetext{
${ }^{3}$ I thank an anonymous reviewer for suggesting I discuss in more detail how the timing problem and the various proposed answers to it connect to the existence condition. I also thank them for pointing me to Bradley's formulation of the timing problem.

${ }^{4}$ Compare the similar claim that Bradley $(2009,75)$ puts to work in objecting to eternalism. Death shouldn't be a unique evil with respect to the timing of its harm.

${ }^{5}$ This allows that a state, such as that of being dead, can harm ${ }_{D}$ without causing anything that is itself a final bad. Rather, a state can be harm $_{D}$ in the sense that it would be better to not be in that state. I thank an anonymous reviewer for prompting me to make this clearer.
} 
Deprivationism: A subject's being dead at $t$ in world $w$ harms $_{\mathrm{D}}$ them if their overall lifetime well-being in $w$ is lower than their overall lifetime wellbeing in a relevant possible world $v$ where they continue to live at $t$ (cf. Feldman 1991, 214-16).

That death can make someone worse off in the sense that their lifetime well-being is lower than it is in a possible life in which they continue to live is sufficient to underwrite its possible badness. Moreover, if death can harm ${ }_{\mathrm{D}}$, then it can also benefit ${ }_{D}$-where that is defined in terms of the subject having less overall lifetime well-being in a relevant possible world than they do in the actual world. This is enough to underwrite death's possible goodness.

Deprivationism is compatible with the weak existence condition because it allows that a subject's well-being is raised or lowered only during times at which they exist and so it allows that a subject is finally benefited or harmed only at times that they exist. Deprivationism holds, instead, that death harms instrumentally. When death harms us, it does so because it prevents various states of affairs from obtaining that would have raised our lifetime well-being. If the Epicurean wants to show that death cannot make the one who dies worse off in the sense of harming $g_{D}$ them, then they must deny that death can make it such that one's life has less overall well-being than it would have had if one had gone on living. This requires something like the strong existence condition. If there is any state of affairs that can be instrumentally good for a subject even if it obtains after that subject's death, then death can harm ${ }_{D}$ them in depriving them of the good of that state of affairs. In a relevant world where they continue to live, that state of affairs can obtain and can thereby increase the overall quality of the subject's life in that world such that it is higher than the overall well-being of their actual life. In the next section, I discuss in more detail how to interpret the strong existence condition such that it blocks deprivationism, but for now, note that whether the Epicurean argues using the no subject problem, the timing problem, or some other argument, they must at least hold something like the strong existence condition-either as an assumption in or an entailment of their theory-in order to block deprivationism.

I am not claiming that harm ${ }_{\mathrm{D}}$ is the only kind of harm. ${ }^{7}$ Perhaps death does not harm us in some other sense of "harm," even though it makes it such that our actual life has higher or lower overall well-being than it would have had otherwise. For instance, Harry Silverstein (1980) holds that the "life-life" comparisons, which are the ones involved in harm $\mathrm{D}_{\mathrm{D}}$, are changing the subject, and instead the proper comparison should be between a continued life and the state of being dead itself. Such "life-death" comparisons might allow the Epicurean to say that death doesn't harm the subject when they're dead, because harms need subjects in order to harm-even if death makes it the case that the subject's life has overall less well-being. Certainly, there might be some senses of "harm" such that death does not harm the one who dies in that proprietary sense. But harm ${ }_{\mathrm{D}}$ is a coherent notion, and comparisons between the overall well-being in one's actual life and in a possible life one would have led are enough to rationally underwrite many of our attitudes toward death. If a subject's death makes their life have lower well-being than it would have had otherwise, it can still be rational for them to regret their death and find it to be an evil. If a subject's death makes their overall life have higher well-being than it would have had otherwise, it can still be rational for them to welcome their death as a relief from suffering. ${ }^{8}$ So long as the deprivationist account can show that death can harm $_{D}$ the one who dies, then Epicurus has failed in offering us a consolationist philosophy. Recall that the Epicurean argument is supposed to establish that death is not an evil and is, indeed, "nothing to us." But if death can make our life have more or less well-being than it would have had

\footnotetext{
${ }^{6}$ Two of the challenges include dealing with overdetermined deaths (McMahan 1988, 44-49; Feldman 1991, 224-26) and measuring the badness of death so that it is not either infinite or infinitesimal (Kagan 2012, chs. 10 and 11). Nothing I say in this paper hinges on particular solutions to these issues.

${ }^{7}$ I leave open that there are distinct senses of harm, such as causal notions discussed by Harman (2009) and the event-based notion discussed by Hanser (2008) and (2011).

${ }^{8} \mathrm{I}$ thank an anonymous reviewer for requesting that I defend in more detail the legitimacy of life-life comparisons.
} 
otherwise, then it is not nothing to us - it's something to us! - given that we care about having more well-being than less. ${ }^{9}$

In the next section, I discuss the strong existence condition in more detail and sketch the most plausible interpretation of it. In the third section, I discuss how this version leads to skepticism about practical reason. In the last section, I discuss how any version strong enough to block deprivationism leads to such a skepticism.

\section{The anti-modal existence condition}

The strong existence condition bans states of affairs that obtain after the time of the subject's death from being good or bad for them, either finally or instrumentally. Deprivationism holds that death can instrumentally harm or benefit us in the sense that it can make our life have more or less overall well-being than it would have had otherwise. Hence, while there might be a variety of arguments for the strong existence condition, ${ }^{10}$ in order to block deprivationism, Epicureans need some version of it that precludes longer possible lives from having more or less well-being than the actual life of the one who dies, so that death cannot be an instrumental harm or benefit. In this section, on behalf of the Epicurean, I articulate the most plausible condition that blocks deprivationism. In the following section, I show how this condition leads to skepticism about practical reason.

The weakest condition is one that simply bans possible states of affairs that obtain after one's death from being final goods or bads, but in order to avoid arbitrariness it should also ban states of affairs that obtain before the time of one's birth from being goods or bads:

Modal existence condition: For any worlds $w$ and $v$ such that $v$ is relevant to $w$, a state of affairs that obtains at time $t$ in $v$ is a final good or bad relative to $s$ in $w$ only if $s$ exists in $w$ at $t$.

This condition entails that relative to a subject in a particular world $w$, possible states of affairs cannot have possible final value if they obtain before the time of the subject's birth or after the time of the subject's death in $w$. The subject's counterpart in some other possible world $v$ can still experience happiness and sadness, undergo success and failure, and these things can still be finally good or bad for the counterpart. But such possible states of affairs cannot be final goods or bads relative to the subject in $w$. They are still possible state of affairs, but they are not finally good or bad for the subject so long as they obtain after the subject's death.

\footnotetext{
${ }^{9}$ Epicurus might be pointing out that we shouldn't imagine our death to be some sort of condition we'll be in post-mortem, as if, somehow, we still exist after death in a sort of bad-or, for that matter, good-state. Lucretius (1951), perhaps, is also getting at something like this in his famous symmetry argument, where he compares death to our prenatal nonexistence and says our attitudes with respect to those should be symmetric. We don't fear prenatal nonexistence, and so we shouldn't fear death. Insofar as their arguments make the sort of claim that death isn't an intrinsically bad state, it's a good one, and so perhaps can provide consolation for those who think death will be "unpleasant" for them. But the deprivationist view isn't that death puts us in an intrinsically bad state, but rather that it is instrumentally bad or good by depriving us of the goods and bads of continued life. I thank an anonymous reviewer for suggesting this reading of Epicurus and Lucretius.

${ }^{10}$ In addition to the no subject problem and the timing problem arguments, the Epicurean might offer the following sorts of arguments. They might offer an inference to the best explanation. It seems that all normal harms and benefits occur while we're alive, so death would be a radically unique sort of harm or benefit. In arguing for subsequentism, Bradley claims that "it seems preferable to have an account of the evil of death that makes its evilness similar to that of the evils of ordinary sicknesses and injuries" (Bradley 2009, 78). The Epicurean might make a similar move, but hold that it is preferable to have an account of harms that makes all of them similar to one another with respect to them requiring the existence of the subject. Another source of support might be a no-welfare-level view, as discussed by Neil Feit (2016). A third could be a view on which there can't be any relations, and hence no value relations, without the existence of the relata-as discussed by Bradley (2009, 80-83). Certainly, there are a variety of ways to defend the strong existence condition. What they all must have in common, however, is that they lead to the denial of deprivationism.
} 
Why isn't it the case that states of affairs are possible final goods or bads for a subject, so long as a counterpart of the subject exists in that possible world and those states of affairs are finally good or bad for their counterpart? It's because the modal existence condition forces us to relativize value to subjects, and so even if relative to a counterpart a state of affairs has value, it's not necessarily the case that relative to the subject that same state of affairs has value. In order to understand this, it helps to invoke relativistic semantics according to which certain propositions have their truth value relativize to contexts of assessment (MacFarlane, 2012; 2014). Consider a possible state of affairs $X$ that obtains in $v$ after the subject $s$ in $w$ no longer exists. As assessed from the context of $s$ in $w$, the proposition $<X$ has final value $>$ has to be false. If $s$ has a counterpart $s^{\star}$ in $v$ that is alive when $X$ obtains, then as assessed from the context of $s^{\star}$ in $v$, the proposition $<X$ has final value $>$ might be true. $X$ is still a possible state of affairs for $s$, but it is not one that is finally good or bad relative to $s$.

To apply the modal existence condition to determine the value of death, take the life of a person in world $w$. To evaluate their death at time $t$, the deprivationist tells us to look at a relevant possible world $v$ in which they live on past $t$, but they have the same lifetime well-being in $v$ at $t$ as they do in $w$ at $t$. But if the modal existence condition holds, then the goods and bads the subject obtains in world $v$ after the time $t$ of their death in $w$ cannot be considered goods and bads from their standpoint in $w$, and so there is nothing to be deprived of in the first place. The value of a part of a different possible life that lies outside the actual lifespan of the person who dies is irrelevant to considering the value of the life of the person who dies. The modal existence condition blocks deprivationism because if there are no possible final goods that obtain after the time of death, then there are no possible goods of which to be deprived by being dead. Therefore, the subject cannot do better overall in a relevant possible world where they continue to live.

Later in the section we'll discuss a stronger condition that holds that no merely possible states of affairs can have value and no actual states of affairs have value if they obtain outside the lifetime of the subject. This stronger anti-modal existence condition entails the modal existence condition in that the latter is strictly a weakening of the former. If the only states of affairs that have value are actual states of affairs that obtain during the lifetime of the subject, then the only possible state of affairs that have value are those that obtain during the lifetime of the subject. But, importantly, the modal existence condition-unlike the anti-modal existence condition-still allows that merely possible states of affairs that obtain while the subject is alive can have value, so we'll assume that it is indeed the case that such states of affairs sometimes have value in order to bring out the differences between the conditions.

For an example of the modal existence condition in action, take the case of Hiking Trip.

Hiking Trip: Subject $s$ has been planning on hiking the Appalachian Trail for months. $S$ drives many hours to the start of the trail, listening to Neil Young's On the Beach for a reason s can't quite figure out. After seventeen hours $s$ finally arrives at the trail head. $S$ gets out of the car, takes a long sniff of the oak-scented air, and has a fatal stroke. If it weren't for the stroke, $s$ would have lived on to finish the trail, enjoying the trip almost the entire time, but then died shortly thereafter from an infected blister.

Given the modal existence condition, the possible life of $s$ in which they hiked the trail can be no better than their actual life, relative to that actual life. The merely possible moments of happiness and exercise of capacities are still possible states of affairs, but they are not possible goods.

However, the modal existence condition is a nonstarter. It allows for arbitrary divergences in the value of one and the same life when relativized to different worlds. To get a grip on the problem, Hiking Trip is represented in Figure 1. Let $L_{s}$ be the shorter possible life of the subject in which they die prior to hiking, and let $L_{L}$ be the longer possible life of the subject in which they die after hiking. $L_{S}$ begins in $w_{S}$ at $t_{0}$ and ends at $t_{1}$, while $L_{L}$ begins in $w_{L}$ at $t_{0}$ and ends at $t_{2}$. Up to $t_{1}, L_{S}$ and $L_{L}$ lead exactly similar lives, with the same amount of overall well-being. Now assume that between $t_{1}$ and $t_{2}$ 


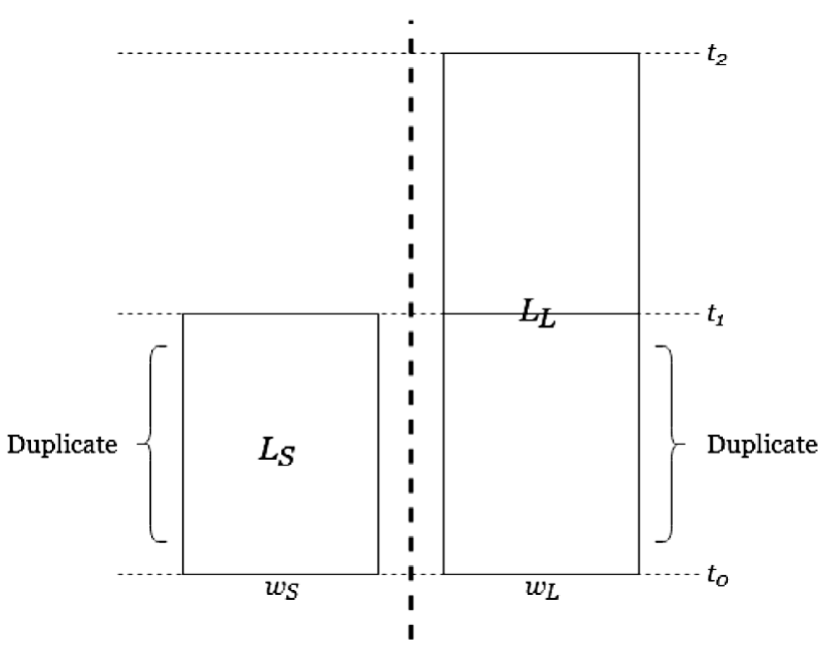

Figure 1. ( $L_{s}$ and $L_{l}$ are duplicates from $t_{0}$ to $t_{1}$, and differ thereafter.)

$L_{L}$ has net positive well-being and, relative to their world and lifetime, the overall value of their life increases.

The problem is that this fact in conjunction with the modal existence condition allows for divergences from the standard formal features of the better than, worse than, and equally good relations. Relative to both worlds and lives, $L_{S}$ and $L_{L}$ are equally good between $t_{0}$ and $t_{1}$. But given that between $t_{1}$ and $t_{2} L_{L}$ is an overall good life relative to that world and lifetime, the modal existence condition allows that $L_{L}$ is better overall than $L_{S}$ relative to $L_{L}$, while $L_{L}$ and $L_{S}$ are equally good overall relative to $L_{S}$. But if $A$ is better than $B$, then $A$ is not equally good as $B$. Of course, the truth of such valuations is sensitive to the world to which they are relativized, so the modal existence condition does not lead to an outright contradiction. But the pattern of the relativized valuation still seems arbitrary in its divergences from the standard formal features of nonrelativized better than and equally good as relations. Given the modal existence condition, $L_{L}$ can treat the entire life of $L_{S}$ as valuable and they can also treat the entirety of their own life as valuable, but $L_{S}$ can treat only a part of the life of $L_{L}$ as valuable. Hence, according to this condition, $L_{L}$ can treat more states of affairs and more entire lives as valuable than $L_{S}$, but it doesn't seem that a longer life in and of itself should let $L_{L}$ treat more things as valuable than $L_{S}$. It doesn't seem that merely a change in the length of a life alone should change the betterness ordering of possible lives relative to a life of a certain length.

The argument suggests that the best version of Epicureanism will commit to something stronger than just the modal existence condition in order to rule out such arbitrary valuations. Hence, it is worthwhile to discuss what the best Epicurean position would look like, because, as we'll see in the third section, the most plausible strengthening of the modal existence condition leads to skepticism about practical reason. Yet, even if you aren't convinced by the preceding argument and think that the Epicurean should only endorse the modal existence condition, we'll see in the fourth section that anything strong enough to entail the modal existence condition, including that condition itself, leads to skepticism about practical reason. The crucial point is that there are a variety of existence conditions the Epicurean can endorse, but, at a minimum, they must all entail the modal existence condition in order to block deprivationism, but this condition leads to skepticism about practical reason.

The Epicurean can and should retain a relativization of value, but they should do so in a nonarbitrary manner. The way to do so is to hold a condition that entails that there are no merely possible goods and bads at all:

Anti-modal existence condition: For any world $w$, a state of affairs is a possible final good or bad relative to $s$ in $w$ only if it obtains in $w$ at time $t$ and $s$ exists at $t$ in $w$. 
This condition holds that only actual states of affairs have value and, therefore, only one's actual life has value. Merely possible states of affairs have no value of which to be deprived, therefore death cannot harm ${ }_{D}$ the one who dies. Note that the anti-modal existence condition entails the modal existence condition. The former holds that only actual states of affairs that occur during the life of the subject have any value, hence any possible state of affairs that has value-namely, only those that are actual-must obtain during the life of the subject. Additionally, the anti-modal existence condition blocks deprivationism. Any finally good or bad state of affairs must obtain at a time that the subject exists, so death cannot deprive the subject of final goods that obtain after the subject dies. There are no merely possible states of affairs that have final value, so there is no possible life in which the subject does better or worse in that life because there is no merely possible life of the subject that has any value at all.

Moreover, the anti-modal existence condition removes the arbitrary elements of the modal existence condition by banning all possible states of affairs from counting as goods or bads of which to be deprived. The modal existence condition allows for merely possible states of affairs to have value, and admitting these in the hiking case allowed for $L_{L}$ to consider the entire life of $L_{S}$ as having value, but $L_{S}$ could not treat the entire life of $L_{L}$ as having value. Given the anti-modal existence condition, such merely possible states of affairs do not have any value for the subject. If one can compare valuable things with things lacking value entirely, then-recalling Figure 1 - the following holds. Relative to $L_{L}$ in $w_{L}, L_{L}$ is better than and not equally good as $L_{S}$, but that is because $L_{S}$ has no value at all relative to $L_{L}$. Relative to $L_{S}, L_{S}$ is better than and not equally good as $L_{L}$, but that is because $L_{L}$ has no value at all relative to $L_{S}$. There is no contradiction in holding that relative to $L_{L}$, $L_{L}$ is better than $L_{S}$ and that relative to $L_{S}, L_{S}$ is better than $L_{L}$ because such valuations are relativized to the different possible lives. Crucially, unlike the pattern generated by the modal existence condition, this pattern is not arbitrary, given that value is symmetrically tied to the actual life of the subject for whom it is valuable.

In the next section, I argue that the anti-modal existence condition leads to a complete or nearly complete skepticism about practical reason, and hence it should be rejected. In the final section, I argue that any view that denies the deprivation account will lead to such skepticism. Hence, any Epicurean view that secures that death cannot make our lives go worse must hold that we are radically mistaken in our practical reasoning.

\section{The anti-modal existence condition and skepticism about practical reason}

The Epicurean is often accused of holding that there is no egoistic reason to continue living. ${ }^{11}$ Yet, so long as the Epicurean is successful in showing that value is conditional on existence due to an existence condition, then this objection loses much of its force. For the Epicurean, continuing to live is not an absolute good because all good is conditional on existence. In this section, I argue against the conditional existence view of the Epicurean by arguing that the most plausible Epicurean condition on value, namely the anti-modal existence condition, leads to skepticism about practical reason. In the

\footnotetext{
${ }^{11}$ See Eric Olson $(2013,73)$ for this claim. He holds that any Epicureanism of more than academic interest would hold, among other things, that "It can never be better to have a longer life than a shorter one" (69) and that "No one can ever have an egoistic reason to go on living, or to avoid or postpone death" (70). However, if the Epicurean holds a view on which value is conditional on existence, such as by holding an existence condition, then these claims are part of their view and so they would embrace this consequence. The point of my paper is to show that such conditional value views lead to skepticism about practical reasoning by the Epicurean's own lights, and so we should reject them. Olson does not posit that Epicureanism leads to skepticism by the Epicurean's own lights. I thank an anonymous reviewer for pushing me to distinguish my argument from Olson's.

Also, see Timmerman (2019) for the claim that any view must accept that there can be self-regarding reasons to continue living if one would get more overall well-being and to stop living if one would get less overall well-being. For more in this general terrain, see Luper $(1987,235)$. And for a critique of this sort of argument, see McMahan $(1988,34-36)$ as well as Rosenbaum $(1989,85-87)$.
} 


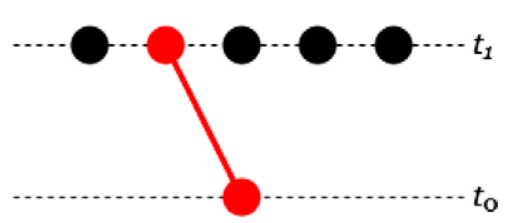

Figure 2. (Line connects the different temporal stages of the actual world.)

next section, I argue that this problem is not unique to the anti-modal existence condition, but to any condition strong enough to block deprivationism. Given that we accept value theoretic views on the basis of our practical reasoning skills, if Epicureanism leads to skepticism with respect to the basis for rationally believing it, then it is a self-undermining view.

My argument for the claim that the anti-modal existence condition leads to skepticism about practical reason goes via an exhaustion of cases. Either the future is fixed or it isn't. In the first case, the anti-modal existence condition results in a nearly complete skepticism about practical reasoning, and in the second case it results in a complete skepticism. Either way, the anti-modal existence condition is in deep tension with practical reasoning. By the future being "fixed," I mean that at any time the fact as to what the actual world will be at any later time is already determined. If the future isn't fixed, there is some time $t_{0}$ such that it isn't already a fact at that time what the actual world will be at some later time $t_{1}$. Given that the future is either fixed or it isn't, then the anti-modal existence condition is in irrevocable conflict with practical reasoning.

Practical reason takes different possible situations to have value. Here's a concrete case:

Deciding Dinner: At time $t_{0}$ subject $s$ is deciding what to cook for dinner at time $t_{1}$. In thinking about what to eat, it seems that $s$ can cook either shepherd's pie with black-eyed peas, lasagna with cashew puree instead of cheese, or mushroom and thyme quiche.

Practical reason tells the subject that a dinner of shepherd's pie at $t_{1}$ has possible value, and similarly for lasagna and quiche. The anti-modal existence condition says that at most one of these things can have value.

If the future is fixed, then from any time it is already a fact what the entire future will actually be. From the time of the birth of a subject, there are no merely possible states of affairs that can obtain, and so given the anti-modal existence condition there are no merely possible goods; see Figure 2. There are only actual states of affairs and actual goods and bads. If the anti-modal existence condition is correct, and the future is fixed, then we are almost always, if not simply always, radically mistaken in our valuations. In Deciding Dinner, at $t_{0}$ subject $s$ takes all the different dinners that $s$ can possibly make to have possible value, but at most only the one $s$ will actually end up making at $t_{1}$ has any possible value relative to $t_{0}$. In general, we take there to be a variety of possible situations with a variety of levels of value, when, according to the anti-modal existence condition, at most only one can have value: the one that will actually occur. The anti-modal existence condition, therefore, would result in a nearly complete skepticism about our reasoning about our own welfare.

Perhaps one thinks the illusion here is not that there is at most one option that has value, but that the future is fixed and so there is at most one option at all. However, even if we think there is only one option that will come about, we generally think other closed off options that will never come about still have value. Even if I know that I will never come to make lasagna, I still think it would be good were I to make it. It is still something that would make my life better were it to happen. But the anti-modal existence condition doesn't license this thought. That merely possible lasagna is not good for me at all.

Moreover, Epicureanism still leads to skepticism about practical reason even if the future is not fixed and so there are multiple open options. If the future is not fixed, then there are some times such that there are distinct possible worlds into which the actual world might evolve at those times. Take 


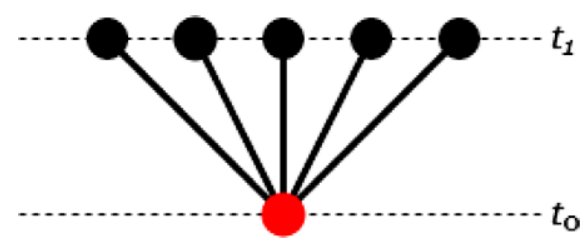

Figure 3. (No world at $t_{1}$ is actual relative to the world at $t_{0}$.)

one of the times $t_{0}$ such that the future at some time $t_{1}$ is not fixed; see Figure 3 . Let's assume that at $t_{0}$ the subject is assessing different possible states of affairs that they might bring about at $t_{1}$. Thus, there are different possible futures relative to the time and world the subject is in and, in these cases, there is no future that is the actual one relative to the subject's present. Because the actual future has yet to be determined, then given the anti-modal existence condition, there cannot be any possible good in any of these scenarios because it is not yet determined which will be the actual one. For instance, if in Deciding Dinner, the future at $t_{1}$ isn't fixed at $t_{0}$, then subject $s$ considers all the different possible dinners to have possible value, but according to the anti-modal existence condition, none of them do. This is not to say merely that the different dinners do not yet have actual value but that they might have value were they to become actual. The anti-modal existence condition entails that none of the possible dinners even has possible value that might become actual value. If the anti-modal existence condition holds, then when a subject is deliberating about possible situations, they will be radically mistaken. They will take there to be possible value in the different potential outcomes, when none of them has any possible value whatsoever.

Either the future is fixed or it isn't, so the anti-modal existence condition results in a complete or nearly complete skepticism about our reasoning about our own welfare. If this most plausible version of Epicureanism were true, then almost all, if not simply all, of our valuations of our own future welfare are radically mistaken. Yet, practical reasoning seems our best guide to value in the first place. How could we come to know whether death can harm us, if we do not have even a basic sense of what makes our life go well? If it were true, then this most plausible Epicureanism would undermine the best source of evidence for assessing its truth.

\section{Epicureanism and skepticism about practical reason}

Yet, is this really a problem for Epicureanism as such, or is it just an issue with the anti-modal existence condition? Might there be other versions of Epicureanism that don't have its implausible consequences for practical reasoning but still entail that death doesn't make the one who dies worse off in the sense of harming ${ }_{D}$ them? Perhaps the Epicurean could hold that additional life can be good but that death cannot be bad (Hershenov 2007). Or maybe they could say that death can be a harm for a person but not a harm to them (Taylor 2012). Or maybe they could believe that either the process of dying or the event of death is bad but that the state of being dead isn't (Rosenbaum 1986). Against these suggestions, I argue that any view that is strong enough to secure that death cannot harm $_{\mathrm{D}}$ us leads to skepticism about practical reason.

As I said at the beginning of section 2, any view that denies deprivationism must hold at least the modal existence condition. Deprivationism holds that death can harm or benefit us in the sense that death can make it such that our lives have higher or lower total well-being than it would have had if we had gone on living. The modal existence condition blocks longer lives from having more or less value relative to the subject who dies, and so, if true, death cannot make it such that our lives have more or less well-being than they would have had otherwise. Hence, the Epicurean must either posit the modal existence condition directly or posit a stronger condition, like the anti-modal existence condition, that entails it. However, any view strong enough to encompass the modal existence condition leads to skepticism about practical reasoning. 
If our decisions never had an impact on the overall quality of our life, then choosing between them would lose much of their meaning. This holds for both pivotal decisions about careers and family, but also for banal decisions about whether to eat lasagna for dinner or whether to try and think up a more interesting example. But those very decisions affect the lengths of our lives in drastic ways of which we are almost always unaware. The decision to eat lasagna or to linger over a sentence, not to mention more momentous decisions about career and family, help determine in radically unpredictable ways how long our life will be.

Schematically, we can represent practical reasoning as choosing between options that lead to a range of different possible lives. Practical reasoning works in part by choosing options based upon the estimated expected value of outcomes, which is a function of the potential value of an outcome and its probability. Without loss of generality, we can assume for the purposes of the argument that this function is simply the product of the value of the outcome and its probability. Say that one is given a choice between three options that each might lead to several different possible lives-for example, a choice of what to make for dinner. Let's assume that one does not believe in and does not apply the modal existence condition, as most of us don't, so that one judges the value of the life as they would be judged relative to that very life. Moreover, let's assume that one is a perfect judge of chances and amounts of well-being and that one assesses the options as follows:

Option 1: 20 percent chance of a life with 100 value points and 80 percent chance of a life with 70 value points, so there is an expected value of 76 points.

Option 2: 30 percent chance of a life with 90 value points and 70 percent chance of a life with 80 value points, so there is an expected value of 83 points.

Option 3: 15 percent chance of a life with 120 value points and 35 percent chance of a life with 90 value points and 50 percent chance of a life with 60 value points, so there is an expected value of 79.5 points.

The estimated expected value of Option 2 is the highest. Thus, assuming we have perfect epistemic access to chances and amounts of well-being, we would generally think it is rational to choose it.

Now assume that the modal existence condition holds and that no stronger existence condition does so in addition. Given the modal existence condition, this reasoning based upon expected value doesn't work unless each possible life is of the exact same length, which almost never is the case. Say that either of the lives in Option 1 are longer than either of the lives in Option 2. And assume, for example, that one chooses Option 2 and ends up with the life that has a $70 \%$ chance of occurring. According to the modal existence condition, nothing that obtains after one's actual time of death can have value, and so the value of the possible lives relative to one's actual life would tend to diverge from the value relative to those possible lives. Grant that the values of the possible lives relative to one's actual life are as follows:

Option 1: 20 percent chance of a life with 120 value points and 80 percent chance of a life with 90 value points, so there is an adjusted expected value of 96 points.

Option 2: 30 percent chance of a life with 90 value points and 70 percent chance of a life with 65 value points, so there is an adjusted expected value of 72.5 points.

Option 3: 15 percent chance of a life with 70 value points and 35 percent chance of a life with 80 value points and 50 percent chance of a life with 65 value points, so there is an adjusted expected value of 71 points.

Given the choice of Option 2, Option 1 has higher expected value. Yet, as discussed in the previous paragraph, we generally think it would be rational to pick Option 2. Thus, the truth of the modal existence condition would condemn our normal practices of prudential deliberation about even the most ordinary matters, not just those pertaining to decisions about life and death. The Epicurean does not just tell us that we are mistaken in our valuations about death, but that we are mistaken in even the most humdrum valuations of what we should make for dinner given that these affect the length of our life. 
However, the more important point that this example brings out is that given the modal existence condition even a nearly ideal Epicurean would be guaranteed to almost always be mistaken in their value judgments. The example shows that we will almost always be radically mistaken in our value judgments, even if we believe in Epicureanism and the modal existence condition, and even if we are perfect calculators of chances and well-being. Take such a calculationally perfect Epicurean, but assume, as will almost always be the case in real life, that they don't know the time of their death. If so, there is no way for them to know which option leads to the most expected value-even given that they apply the modal existence condition and calculate chances and well-being perfectly. For the sake of presentation, let us assume that the Epicurean agent has no evidence that would tell her how long she lives in each of the three options. Then, the agent would presumably operate under the assumption that each option leads to a life of the exact same length. But then given the modal existence condition, she would choose Option 2 because that has highest expected value under the assumption that all the lives are of equal length, even though Option 1 has the highest expected value given the length of their life were they to choose Option 2. By the Epicurean's own lights, a nearly ideal agent who believed in the modal existence condition would choose Option 2, even though choosing it leads to less expected value than Option 1. Of course, this example where all of the options together canvass only seven possible lives is just a toy. In the vast majority of cases, there will be a host of possible lives confronting the agent and very little information as to how long each possible life would be.

If the modal existence condition holds, then we are almost always mistaken in our calculations of expected value, even given perfect knowledge of potential well-being and its chance of obtaining, let alone given our actual imperfect access to such facts. Adding further conditions that make the Epicurean view more compelling will only lead to greater skepticism, as evidenced by the problems of the anti-modal existence condition. Any implementation of Epicureanism strong enough to secure that death cannot make us worse off in the sense of it being unable to deprive us of goods us will lead to a nearly complete, or simply complete, skepticism about practical reason. But if practical reason is hopelessly mistaken, then what guide can it be to choosing a proper view of the value of death? Epicureanism is self-defeating in undermining the epistemic basis for rational belief in itself. I have more confidence that our practical reasoning has a modicum of reliability than I do that death can never make us worse off.

Acknowledgments. I would like to thank the audience at the 2016 conference of the International Association of the Philosophy of Death and Dying for discussion on a nascent form of this paper. For comments on earlier drafts, I thank Ben Bronner, Carolina Flores, Tyler John, Frances Kamm, Kyle Landrum, Ezra Rubenstein, Travis Timmerman, and Jonathon VandenHombergh. For extensive early discussion, I thank Jimmy Goodrich and Pavel Nitchovski. For multiple rounds of feedback, I thank Alex Guerrero and Larry Temkin. Finally, I want to thank two anonymous reviewers for this journal for their helpful comments.

Christopher Frugé is a PhD student at Rutgers University. His primary research interests include metaphysics, meta-ethics, and ethics.

\section{References}

Bradley, Ben. 2009. Well-being and Death. New York: Oxford University Press.

Epicurus. 1997. In Greek and Roman Philosophy after Aristotle, edited by J. L. Saunders. New York: Free Press.

Feldman, Fred. 1991. "Some Puzzles about the Evil of Death." The Philosophical Review 100 (2): 205-27.

Feit, Neil. 2016. "Comparative Harm, Creation and Death." Utilitas 28 (2): 136-63.

Green, O. H. 1982. "Fear of Death.” Philosophy and Phenomenological Research 43 (1): 99-105.

Hanser, Matthew. 2008. “The Metaphysics of Harm.” Philosophy and Phenomenological Research 77 (2): 421-50.

Hanser, Matthew. 2011. "Still More on the Metaphysics of Harm." Philosophy and Phenomenological Research 82 (2): $459-69$.

Harman, Elizabeth. 2009. "Harming as Causing Harm.” In Harming Future Persons, edited by M. A. Roberts and D. T.

Wasserman, 137-54. Dordrecht: Springer Verlag.

Hershenov, David. 2007. “A More Palatable Epicureanism.” American Philosophical Quarterly 44 (2): 171-80. 


\section{C. Frugé}

Johansson, Jens. 2012. “The Timing Problem.” In The Oxford Handbook of Philosophy of Death, edited by Ben Bradley, Fred

Feldman, and Jens Johansson, 255-73. New York: Oxford University Press.

Kagan, Shelly. 2012. Death. New Haven, CT: Yale University Press.

Lucretius. 1951. On the Nature of the Universe. Translated by R. Latham. London: Penguin Classics.

Luper, Steven. 1987. “Annihilation.” The Philosophical Quarterly 37 (148): 233-52.

Luper, Steven. 2007. “Mortal Harm.” The Philosophical Quarterly 57 (227): 239-51.

MacFarlane, John. 2012. "Relativism.” In The Routledge Companion to the Philosophy of Language, edited by G. Russell and D. Graff Fara, 132-42. New York: Routledge.

MacFarlane, John. 2014. Assessment Sensitivity. New York: Clarendon Press.

McMahan, Jeff. 1988. "Death and the Value of Life." Ethics 99: 32-61.

Nagel, Thomas. 1994. "Death.” In Language, Metaphysics, and Death 2nd ed., edited by J. Donnelly, 21-29. New York: Fordham University Press.

Olson, Eric. 2013. “The Epicurean View of Death.” Journal of Ethics 17: 65-78.

Pitcher, George. 1984. “The Misfortunes of the Dead.” American Philosophical Quarterly 21 (2): 183-88.

Purves, Duncan. 2017. “Desire Satisfaction, Death, and Time.” Canadian Journal of Philosophy 47 (6): 799-819.

Rosenbaum, Stephen. 1986. "How to Be Dead and Not Care: A Defense of Epicurus.” American Philosophical Quarterly 23 (2): 217-25.

Rosenbaum, Stephen. 1989. "Epicurus and Annihilation.” The Philosophical Quarterly 39 (154): 81-90.

Silverstein, H. S. 1980. “The Evil of Death.” The Journal of Philosophy 77 (7): 401-24.

Taylor, J. S. 2012. Death, Posthumous Harm, and Bioethics. New York: Routledge.

Timmerman, Travis. 2019. “A Dilemma for Epicureanism.” Philosophical Studies 176 (1): 241-57. 